\title{
A retrospective study of clinical features of cough variant asthma in Chinese adults
}

\author{
Weiping Liu ${ }^{1 *} \mathbb{D}$, Huaping Chen ${ }^{2}$, Dehua Zhang ${ }^{1}$, Feng $\mathrm{Wu}^{1}$ and Liqin Zhou ${ }^{1}$
}

\begin{abstract}
Background: Clinical features of cough variant asthma (CVA) in Chinese adults are largely uncertain.

Methods: A total of 303 patients newly diagnosed as uncontrolled asthma (symptom control and future risk of adverse outcomes), including 175 CVA and 128 classic asthma (CA), were enrolled in this retrospective survey. Clinical features including basic characteristics, pulmonary function, airway hyperresponsiveness (AHR) and cell counts of induced sputum, were compared retrospectively. All patients were classified into four inflammatory subtypes based on the counts of induced sputum eosinophils and neutrophils as eosinophilic (E), neutrophilic (N), mixed granulocytic $(M)$, and paucigranulocytic (P) subtypes. Inflammatory subtype distribution was also compared.

Results: Compared with CA patients, CVA patients were younger $(P=0.009)$, had a higher prevalence of female patients $(P=0.001)$, higher parameter values of baseline pulmonary function $(P \leq 0.01$ for all), shorter duration of disease $(P=0.002)$, lower AHR $(P=0.001)$ and lower sputum eosinophil\% $(P=0.009)$. There was a difference in the AHR distribution as the percentage of moderate and severe AHR in CVA was significantly lower than in CA (41.72\% VS $64.70 \%, P=0.001)$. The inflammatory subtype distribution was different as the proportion of $E$ and $M$ subtypes in CVA was lower than in CA $(56.0 \%$ vs $67.19 \%, P=0.049)$. The proportion of subtype $P$ was the lowest and subtype $M$ was the highest in both CVA and CA patients. There was a similar negative correlation of sputum eosinophil\% with AHR in CVA and $C A(r=-0.337, P<0.0001$ and $r=-0.27, P=0.026$, respectively), and a positive correlation between sputum eosinophil\% and improvement rate of $\mathrm{FEV}_{1}$ after inhalation of bronchodilator $\left(\triangle \mathrm{FEV}_{1} \%\right)(r=0.33, \mathrm{P}=0.01)$.
\end{abstract}

Conclusions: CVA patients showed a better pulmonary function and lower airway inflammation in contrast to CA patients, which may participate in the pathogenesis of chronic cough in CVA.

Keywords: Cough variant asthma (CVA), Classic asthma (CA), Induced sputum eosinophils, Pulmonary function, Airway hyperresponsiveness (AHR)

\section{Background}

Many patients in clinics are suffering from a chronic cough, which is defined as cough being the sole or predominant symptom lasting for at least 8 weeks, with absence of pulmonary disease [1]. Chronic cough is one of the commonest symptoms for which adults seek medical care worldwide. Studies have shown that CVA is one of the most common causes of chronic non-productive cough, as well as gastroesophageal

\footnotetext{
*Correspondence: abcliuweiping@qq.com

${ }^{1}$ Department of Respiratory Medicine, Huizhou Third People's Hospital, Guangzhou Medical University, 1\# Xuebei Avenue, Huizhou 516002,

Guangdong, China

Full list of author information is available at the end of the article
}

reflux-associated cough, upper airway cough syndrome (UACS) and eosinophilic bronchitis (EB)-induced cough [2-4]. A prospective and multicenter survey in 2015 demonstrated that nearly one-third of chronic cough was associated with CVA in China [5], which was higher than that reported in western countries. However, CVA is easily overlooked and misdiagnosed clinically, since it presents with only cough but no wheezing as in CA.

Airway inflammation in asthma is heterogeneous. It is important to fully understand its pathophysiology and clinical phenotypic characteristics for the investigation of pathogenesis and development of treatment strategies. Nevertheless, as we know, the majority of current researches are relevant to classic asthma, and non-typical

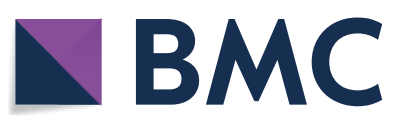

(c) The Author(s) 2019. This article is distributed under the terms of the Creative Commons Attribution 4.0 International License (http://creativecommons.org/licenses/by/4.0/), which permits unrestricted use, distribution, and reproduction in any medium, provided you give appropriate credit to the original author(s) and the source, provide a link to the Creative Commons license, and indicate if changes were made. The Creative Commons Public Domain Dedication waiver (http://creativecommons.org/ publicdomain/zero/1.0/) applies to the data made available in this article, unless otherwise stated. 
asthma patients are often excluded. Studies of CVA are few and the sample size is small [6-9]. Therefore, we conducted a retrospective study with a larger sample size to investigate: (1) the differences in clinical features between CVA and CA patients, by analyzing basic characteristics, pulmonary function, AHR, and cell counts of induced sputum; (2) the correlation between sputum eosinophil\% and AHR or airway reversibility.

\section{Methods}

\section{Subjects}

Newly diagnosed asthma patients who visited respiratory clinics of Affiliated Third People's Hospital of Guangzhou Medical University in Huizhou, were retrospectively included in this study from June 2016 to December 2017. All subjects were at uncontrolled stage. The level of asthma control was defined by asthma symptoms control (in the past 4 weeks, has the patient had daytime asthma symptoms more than twice/week and/or any night waking due to asthma and/or any activity limitation due to asthma and/or reliever needed for symptoms' more than twice/week) and future risk of adverse outcomes (in the past 4 weeks, has the patient had $\mathrm{FEV}_{1} \%$ less than normal predicted value and/or any severe exacerbation due to asthma). Uncontrolled asthmatic patient had equal to or greater than 3 features as the above.

According to the 2018 GINA Guidelines of Asthma Management and Prevention [10], we divided all subjects into CVA group and CA group based on clinical symptoms and AHR test or bronchodilator reversibility test. CVA was diagnosed according to the following criteria: patients had a clinical history of a persistent cough (longer than 8 weeks) and AHR, but had no wheezing or dyspnea in contrast to CA, bronchodilators were effective against their coughs, excluding other diseases that caused chronic cough, such as gastroesophageal reflux, UACS, EB, taking angiotensin-converting enzyme inhibitors, etc. Patients with chronic cough and sputum productive of eosinophils who improve with inhaled corticosteroids (ICS) are often labelled as having EB. However, EB has no airway hyperresponsiveness as in CVA. All CVA subjects collected were tested with positive airway responsiveness, therefore, EB patients could be excluded from this study. CA was diagnosed based on the evidence of recurrent wheezing, shortness of breath, with or without chest tightness or cough, and reversible airway obstruction or AHR.

All subjects included had not received anti-asthma therapy before this study (including oral or inhaled corticosteroid, leukotriene receptor antagonists, antihistamines, etc.), and had no past history of upper respiratory tract infection in the last month. Result of chest radiograph or chest computed tomography was normal, excluding lung diseases (pneumonia, lung cancer, pulmonary tuberculosis, etc.). All subjects were over 17 years old, and had the cognitive competence to pass all the medical examinations under the guidance of doctors.

\section{Study design}

Each subject underwent a clinical history inquiry, physical examination and imaging examination (chest radiography or computed tomography), pulmonary function test (PFT), AHR test or bronchodilator reversibility test, and finally sputum induction on the same day.

\section{PFT and AHR test}

PFT, methacholine challenge test (AHR test), and bronchodilator reversibility test were performed with a computerized spirometer (MS-pneumo+aps, Jaeger, German) by professional technicians according to the 2014 Guideline for Pulmonary Function of Chinese Respiratory Society [11]. The forced expiratory volume in $1 \mathrm{~s}\left(\mathrm{FEV}_{1}\right)$, forced vital capacity $(\mathrm{FVC}), \mathrm{FEV}_{1} / \mathrm{FVC}$ ratio, maximal mid-expiratory flow (MMEF) and maximum forced expiratory flow (MEF) were recorded in PFT. The degree of central airways obstruction was divided into four levels based on $\mathrm{FEV}_{1} \%$ predicted value: mild ( $\left.\geq 70 \%\right)$, moderate $(60-69 \%)$, between moderate and severe $(50-$ $59 \%)$, severe (35-49\%), extremely severe $(<35 \%)$ [11].

AHR test was performed after PFT. Patients were asked to inhale gradually increasing doses of methacholine (0.9\% saline, $0.078,0.312,1.125$ and $2.504 \mathrm{mg})$, and $\mathrm{FEV}_{1}$ was measured after each inhalation. This test was stopped until a reducing in baseline $\mathrm{FEV}_{1}$ of $20 \%$. AHR was calculated by $\mathrm{PD}_{20}-\mathrm{FEV}_{1}$ (cumulative dose of methacholine required to achieve a $20 \%$ decrease in $\mathrm{FEV}_{1}$ ) and defined by $\mathrm{PD}_{20}-\mathrm{FEV}_{1} \leq 2.504 \mathrm{mg}$. AHR was divided into four levels based on $\mathrm{PD}_{20}-\mathrm{FEV}_{1}$ value: very mild (1.076-2.504 mg), mild (0.294-1.075 mg), moderate $(0.035-0.293 \mathrm{mg})$, severe $(<0.035 \mathrm{mg})$ [11].

\section{Bronchodilator reversibility test}

This test was performed on patients whose $\mathrm{FEV}_{1} \%$ predicted value $<70 \%$ in PFT. Patients were required to inhale $400 \mu \mathrm{g}$ salbutamol through an inhalation device, and repeated the aforementioned PFT after $20 \mathrm{~min}$. The result was defined as positive (reversible airflow obstruction) if postbronchodilator $\mathrm{FEV}_{1}$ increased $\geq 12 \%$ and absolute value increased $\geq 200 \mathrm{ml}$ of prebronchodilator, moreover, postbronchodilator $\mathrm{FEV}_{1} /$ $\mathrm{FVC}<70 \%[11]$. 


\section{Sputum induction and sputum cell counts}

Before inducing sputum by the ultrasonic atomizer, patients were required to inhale $400 \mu \mathrm{g}$ salbutamol. According to an established method [12], patients were asked to slowly inhale a single concentration of $3 \%$ hypertonic saline for $30 \mathrm{~min}$, then rinsed the mouth with water, coughed deeply, and expectorated sputum into a sterile container. The opaque and high-density part of sputum sample was collected and diluted with $0.1 \%$ dithiothreitol in a water bath $\left(37{ }^{\circ} \mathrm{C}\right)$ for $15 \mathrm{~min}$, vortexed $1 \mathrm{~min}$, and filtered through a 300 mesh fiber. After centrifuged at $3000 \mathrm{r} / 10 \mathrm{~min}$, sputum cells were collected to prepare a Hematoxylin-Eosin-stained smear for the cells classification. Cells were counted with the percentage of 400 sputum cells under the microscope. A sputum sample was regarded as qualified for analysis when squamous epithelial cell contamination was $<10 \%$ and viable cell was $>80 \%$.

\section{Statistical analysis}

All data were analyzed using SPSS version 19.0 (USA) and $\mathrm{P}<0.05$ was considered of statistical significance. Continuous variables were expressed as mean (SD) depending on normal distribution or median (interquartile range) for non-normal distribution, while classification variables analyzed with Chi square test were expressed as number (percentage). Two groups of continuous variables were compared with T-test (normal distribution) or Mann-Whitney $U$ test (non-normal distribution). Correlation between sputum eosinophils\% and AHR or bronchodilator reversibility was analyzed by Spearman rank correlation.

\section{Results}

Differences in basic features and pulmonary function between CA and CVA patients

Of the 200 subjects in CVA and 140 subjects in CA enrolled, twenty-five CVA and twelve CA patients were excluded due to failed sputum induction. 175 CVA subjects (63 males and 112 females, all received AHR test) and 128 CA subjects (71 males and 57 females, 68 subjects received AHR test and 60 subjects received bronchodilator reversibility test) were included in this analysis, both with the ages ranged from 17 to 84 years old. CVA subjects consisted of young adults (1739 years, $\mathrm{n}=79)$, middle-age adults $(40-59$ years, $\mathrm{n}=54)$ and elderly adults $(60-79$ years, $n=42)$. CA subjects consisted of young adults $(17-39$ years, $n=29)$, middleage adults $(40-59$ years, $\mathrm{n}=60)$ and elderly adults $(60-$ 79 years, $\mathrm{n}=39$ ).

As shown in Tables 1 and 2, CVA patients were significantly younger $(\mathrm{P}=0.009)$ and presented a significantly higher prevalence of female $(64 \%$ vs $44.5 \%$,
Table 1 Basic features of asthma patients

\begin{tabular}{lccl}
\hline Data & CVA $(\mathbf{n}=\mathbf{1 7 5})$ & CA $(\mathbf{n}=128)$ & P \\
\hline Age (year) & $46.25(17.30)$ & $51.34(14.81)$ & 0.009 \\
Female, $\mathrm{n}(\%)$ & $112(64)$ & $57(44.5)$ & 0.001 \\
Smoker, n (\%) & $30(17.14)$ & $25(19.53)$ & 0.594 \\
Chronic cough, n (\%) & $175(100)$ & $101(78.91)$ & 0.0002 \\
Duration (month) & $26.21(51.06)$ & $61.64(97.18)$ & 0.002 \\
Height (cm) & $157.22(12.82)$ & $159.56(8.44)$ & 0.057 \\
Weight (kg) & $59.68(11.57)$ & $61.12(9.55)$ & 0.248 \\
Body mass index (BMl, kg/m²) & $23.33(3.78)$ & $23.86(3.52)$ & 0.23 \\
\hline
\end{tabular}

Data are expressed as mean (SD) or number (percentage)

CVA cough variant asthma, CA classic asthma

$\mathrm{P}=0.001$ ), as well as a shorter duration of disease $(\mathrm{P}=0.002)$ than $\mathrm{CA}$ patients. In addition to wheezing, nearly $80 \%$ of CA patients had a history of chronic cough. All indices of pulmonary function in CVA were significantly higher than in $\mathrm{CA}(\mathrm{P}<0.01$ for all).

\section{Differences in distribution of AHR between CA and CVA patients}

The AHR of CVA was significantly lower than CA $(P=0.001)$. There was a difference in the AHR distribution as the percentage of moderate and severe AHR in CVA was significantly lower than in CA $(41.72 \%$ VS $64.70 \%, P=0.001)$ (Table 3$)$.

\section{Differences in induced sputum cell counts and inflammatory subtype distribution between CA} and CVA patients

Sputum eosinophil\% in CVA was significantly lower than in $\mathrm{CA}(\mathrm{P}=0.009)$, while an opposite result was showed in the macrophage $\%(P=0.0004)$. No significant difference in sputum neutrophil\% $(\mathrm{P}=0.128)$ or lymphocyte\% $(\mathrm{P}=0.058)$ was found.

According to induced sputum eosinophil\% (eos) and neutrophil\% (neu), all patients were classified into four subtypes: eosinophilic (E) (eos\% $\geq 2.5$, neu\% $<65)$, neutrophilic $(\mathrm{N}) \quad(\operatorname{eos} \%<2.5$, neu\% $\geq 65)$, mixed granulocytic (M) $(e o s \% \geq 2.5$, neu\% $\geq 65)$ and paucigranulocytic (P) $($ eos $\%<2.5$, neu $\%<65)$ subtypes. There was a difference in the inflammatory subtype distribution as the proportion of $E$ and $M$ subtypes in CVA was lower than in CA $(56.0 \%$ vs $67.19 \%, \mathrm{P}=0.049)$. The proportion of subtype $\mathrm{P}$ was the lowest and subtype $\mathrm{M}$ was the highest in both CVA and CA (Table 4).

\section{Correlation between sputum eosinophil\% and AHR or airway reversibility}

Significant and similar correlations were found between sputum eosinophil\% and AHR in CVA and CA $(r=-0.337, P<0.0001$, and $r=-0.27, P=0.026$, 
Table 2 Pulmonary function of asthma patients

\begin{tabular}{lccc}
\hline Data & CVA $(\mathbf{n}=\mathbf{1 7 5})$ & CA $(\mathbf{n}=1 \mathbf{1 2 8})$ & P \\
\hline FEV $_{1}(\mathrm{~L})$ & $2.28(0.72)$ & $1.72(0.62)$ & $<0.0001$ \\
FVC $(\mathrm{L})$ & $3.01(0.92)$ & $2.73(0.79)$ & 0.006 \\
FEV $_{1} \%$ predicted value & $87.75(11.49)$ & $65.69(20.97)$ & $<0.0001$ \\
FVC \% predicted value & $97.36(13.39)$ & $85.25(18.32)$ & $<0.0001$ \\
FEV $_{1} /$ FVC (\%) & $74.77(9.65)$ & $61.25(12.95)$ & $<0.0001$ \\
PEF \% predicted value & $88.89(15.54)$ & $66.76(21.70)$ & $<0.0001$ \\
MMEF (L/sec) $_{\text {MEF }_{50 \%} \% \text { predicted value }}$ & $1.83(0.92)$ & $1.03(0.63)$ & $<0.0001$ \\
MEF $_{25 \%} \%$ predicted value & $48.50(23.79)$ & $32.36(19.00)$ & $<0.0001$ \\
\hline
\end{tabular}

Data are expressed as mean (SD)

CVA cough variant asthma, CA classic asthma, FEV forced expiratory volume in one second, FVC forced vital capacity, PEF peak expiratory flow, MMEF maximal mid-expiratory flow, MEF $25 \%$ maximum forced expiratory flow at $25 \%$ FVC, MEF50\% maximum forced expiratory flow at 50\% FVC

Table 3 Distribution of AHR in asthma patients

\begin{tabular}{lcrl}
\hline Data & CVA $(\mathbf{n}=\mathbf{1 7 5})$ & CA $(\mathbf{n}=\mathbf{6 8})$ & P \\
\hline $\mathrm{PD}_{20}-\mathrm{FEV}_{1}(\mathrm{mg})$ & $0.73(0.76)$ & $0.42(0.61)$ & 0.001 \\
Level of AHR & & & \\
$\quad$ Very mild, $\mathrm{n}(\%)$ & $37(21.14)$ & $8(11.76)$ & 0.001 \\
Mild, $\mathrm{n}(\%)$ & $65(37.14)$ & $16(23.54)$ & \\
Moderate, $\mathrm{n}(\%)$ & $53(30.29)$ & $25(36.76)$ & \\
Severe, $\mathrm{n}(\%)$ & $20(11.43)$ & $19(27.94)$ & \\
\hline
\end{tabular}

Data are expressed as mean (SD) or number (percentage); the proportion of moderate and severe AHR was compared with Chi square test

CVA cough variant asthma, $C A$ classic asthma, $A H R$ airway hyperresponsiveness

Table 4 Results of induced sputum cell counts and inflammatory subtypes

\begin{tabular}{lccc}
\hline Data & CVA (n=175) & CA (n=128) & P \\
\hline Cell counts & & & \\
Eosinophil (\%) & $3.26(12.78)$ & $5.24(19.08)$ & 0.009 \\
Neutrophil (\%) & $77.14(34.57)$ & $80.8(31.55)$ & 0.128 \\
Macrophage (\%) & $10.79(22.87)$ & $6.35(13.89)$ & 0.0004 \\
Lymphocyte (\%) & $0.64(1.48)$ & $0.56(1.14)$ & 0.058 \\
Inflammatory subtypes & & & \\
Eosinophilic, n (\%) & $42(24.0)$ & $32(25.0)$ & \\
Mixed granulocytic, n (\%) & $56(32.0)$ & $54(42.19)$ & 0.049 \\
Neutrophilic, n (\%) & $54(30.86)$ & $41(32.03)$ & \\
Paucigranulocytic, n (\%) & $23(13.14)$ & $1(0.78)$ & \\
\hline
\end{tabular}

The results of cell counts are expressed as median (interquartile range) and compared with Mann-Whitney $\mathrm{U}$ test

Inflammatory subtypes are expressed as number (percentage) and compared with Chi square test

CVA cough variant asthma, $C A$ classic asthma respectively). There was also a significant correlation of sputum eosinophil\% with the improvement rate in $\mathrm{FEV}_{1}$ after inhalation of bronchodilator $\left(\triangle \mathrm{FEV}_{1} \%\right)$ in $\mathrm{CA}$ patients $(\mathrm{r}=0.33, \mathrm{P}=0.01)$ (Fig. 1).

\section{Discussion}

This is the first large-sample study on the clinical features of CVA patients in Chinese adults. With a broad range of all ages, a total of 175 CVA patients aged 17-84 years were evaluated in this study. Our study is superior to previous studies in such a broad range of all ages and a larger sample size. Therefore, the results of our study are reliable and may reflect the reality in practice.

This study retrospectively compared the baseline pulmonary function, AHR, and induced sputum cell counts in asthma patients. It showed that: (1) the parameter values of baseline pulmonary function in CVA, including indices of both central and peripheral airways obstruction, were significantly higher than in CA; (2) as with CA, eosinophilic airway inflammation (sputum eosinophil\% $\geq 2.5$ ) was also an important pathological feature of CVA; nevertheless, the AHR and eosinophilic airway inflammation of $\mathrm{CA}$ were significantly higher than those of CVA. These findings may be related to the mechanism of chronic cough without wheeze in CVA in contrast with CA. Some studies, with a small sample size, revealed that these factors, such as airflow obstruction at central airways, heightened cough sensitivity, higher wheezing threshold, lower AHR, prostaglandin- $E_{2}$ and neuropeptide substance $P$ secreted by eosinophils, mild airway remodelling, lower total IgE and smaller numbers of sensitized allergens [13-19] were considered to be associated with cough without wheeze in CVA. However, these possible mechanisms of chronic cough are controversial and the exact mechanism remains unclear. With a larger sample size and adults of all age levels involved, our study demonstrated that lower AHR, lower eosinophilic inflammation, and mild airflow obstruction were associated with presenting manifestations in CVA.

There is also a controversy on peripheral or central airways obstruction of CVA. We noticed that 51.43\% of CVA subjects showed normal or almost normal pulmonary function (only with peripheral rather than central airways obstruction at baseline), and other subjects had a mild central airways obstruction $\left(\mathrm{FEV}_{1} \%\right.$ predicted value $\geq 70 \%$ ); while $87.5 \%$ of $\mathrm{CA}$ patients showed a central airways obstruction, and $56.2 \%$ of CA patients had moderate to extremely severe central airways obstruction $\left(\mathrm{FEV}_{1} \%\right.$ predicted value $\left.\leq 69 \%\right)$. These results indicate that there is no relationship between the site of airway obstruction (peripheral or central airways) and chronic cough mechanism of CVA. 

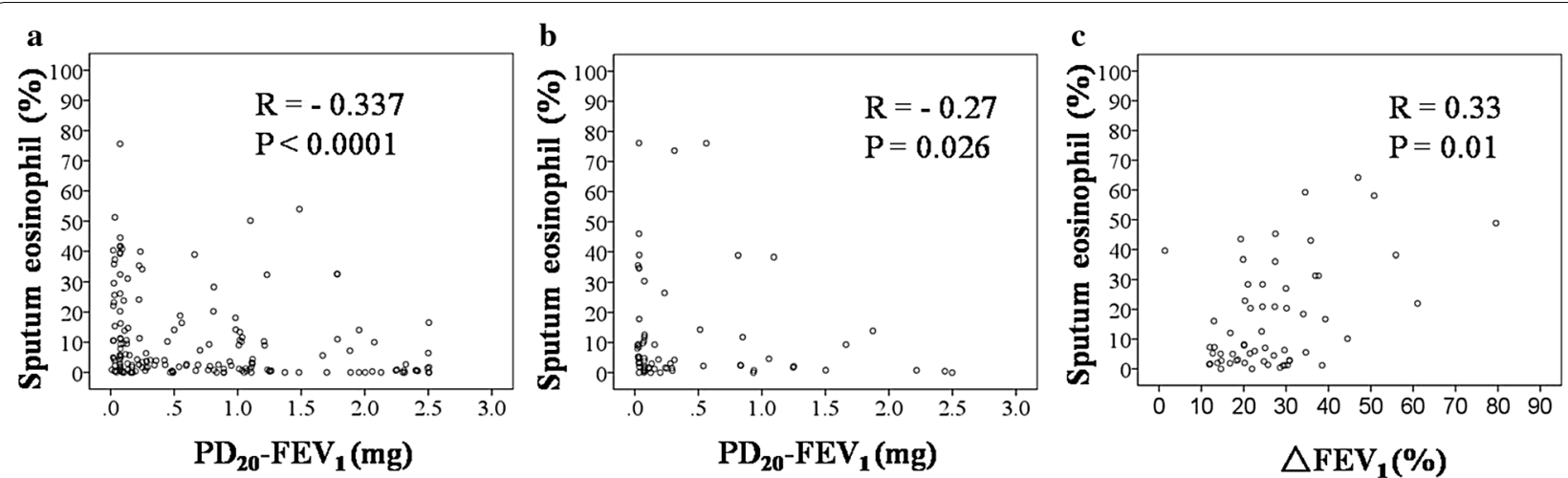

Fig. 1 Correlation between sputum eosinophil\% and $\mathrm{PD}_{20}-\mathrm{FEV}$, in CVA patients (a) or in CA patients (b). Correlation between sputum eosinophil\% and the improvement rate in $\mathrm{FEV}_{1}$ after inhalation of bronchodilator in CA patients (c)

Induced sputum cell counts, a convenient and non-invasive method, is considered more accurate in assessing airway eosinophilic inflammation when compared with fractional exhaled nitric oxide (FeNO) and peripheral blood eosinophil count. There is no unified classification standard for sputum cell counts in Chinese and Westerners. According to the definition of sputum eosinophil $\% \geq 2.5$ as eosinophilic inflammation and neutrophil\% $\geq 65$ as neutrophilic inflammation recommended in 2016 Chinese National Guidelines on Diagnosis and Management of Cough [20], asthma patients were classified into four cell subtypes, which provided more evidence for individualized treatment. ICS is effective for eosinophilic asthma, but poor for noneosinophilic asthma. Our study found that 44\% CVA and $32.81 \%$ CA patients were diagnosed as non-eosinophilic asthma; thus, these patients needed more treatment strategies to control airway inflammation, in addition to ICS.

Our study has some limitations. First, it was conducted in a retrospective fashion. Second, sputum neutrophil might increase by smoking cigarette, age and air pollution, while the sample size was significantly increased if smoking and non-smoking patients were included in this study.

\section{Conclusions}

CVA patients showed higher parameter values of baseline pulmonary function, lower airway reactivity and airway eosinophilic inflammation in contrast to CA, which may correlate with the pathogenesis of chronic cough in CVA.

\section{Abbreviations}

CVA: cough variant asthma; $C A$ : classic asthma; $\mathrm{FEV}_{1}$ : forced expiratory volume in one second; FVC: forced vital capacity; PEF: peak expiratory flow; MMEF: maximal mid-expiratory flow; PEF: peak expiratory flow; MEF $25 \%$ : maximum forced expiratory flow at 25\% FVC; MEF50\%: maximum forced expiratory flow at 50\% FVC; AHR: airway hyperresponsiveness; PFT: pulmonary function test; $\triangle \mathrm{FEV}, \%$ : the improvement rate in $\mathrm{FEV}_{1}$ after inhalation of bronchodilator; UACS: upper airway cough syndrome; EB: eosinophilic bronchitis; ICS: inhaled corticosteroids.

\section{Authors' contributions}

Contributions: (I) Conception and design: WL, FW, LZ; (II) Administrative support: FW; (III) Provision of study materials or patients: DZ; (IV) Collection and assembly of data: $\mathrm{HC}_{\text {; }}(\mathrm{V})$ Data analysis and interpretation: WL; (VI) Manuscript writing: WL. All authors read and approved the final manuscript.

\section{Author details}

${ }^{1}$ Department of Respiratory Medicine, Huizhou Third People's Hospital, Guangzhou Medical University, 1\# Xuebei Avenue, Huizhou 516002, Guangdong, China. ${ }^{2}$ Department of Reproductive Medicine, Huizhou Central People's Hospital, National Sun Yat-sen University, Huizhou, Guangdong, China.

\section{Acknowledgements}

Not applicable.

\section{Competing interests}

The authors declare that they have no competing interests.

\section{Availability of data and materials}

The datasets used or analyzed in the present study are available from the corresponding author on reasonable request.

\section{Consent for publication \\ Not applicable.}

\section{Ethics approval and consent to participate}

The protocol for this study was approved by the Ethics Committee of the Third People's Hospital of Guangzhou Medical University in Huizhou, and it conforms to the provisions of in accordance with the Helsinki Declaration as revised in 2013. This study absolved the need of informed consent from patients, as the study was a retrospective study with identification data anonymized.

\section{Funding}

Not applicable.

\section{Publisher's Note}

Springer Nature remains neutral with regard to jurisdictional claims in published maps and institutional affiliations.

Received: 22 July 2018 Accepted: 8 January 2019

Published online: 17 January 2019 


\section{References}

1. Pratter $M R$, Brightling $C E$, Boulet $L P$, et al. An empiric integrative approach to the management of cough: ACCP evidence-based clinical practice guidelines. Chest. 2006;129:222S-31S.

2. Desai $D$, Brightling C. Cough due to asthma, cough-variant asthma and non-asthmatic eosinophilic bronchitis. Otolaryngol Clin North Am. 2010;43:123-30

3. Ichinose $M$, Sugiura $H$, Nagase $H$, et al. Japanese guidelines for adult asthma 2017. Allergol Int. 2017;66:163-89.

4. Chung KF, Pavord ID. Prevalence, pathogenesis, and causes of chronic cough. Lancet. 2008;371:1364-74.

5. Lai K, Chen R, Lin J, et al. A prospective, multicenter survey on causes of chronic cough in China. Chest. 2013;143:613-20.

6. Matsuoka H, Niimi A, Matsumoto H, et al. Inflammatory subtypes in cough-variant asthma: association with maintenance doses of inhaled corticosteroids. Chest. 2010;138:1418-25.

7. Okada C, Horiba M, Matsumoto H, et al. A study of clinical features of cough variant asthma. Int Arch Allergy Immunol. 2001;125(Suppl 1):51-4.

8. Tang W, Zhou J, Miao L, et al. Clinical features in patients of cough variant asthma with normal and high level of exhaled fractional nitric oxide. Clin Respir J. 2016. https://doi.org/10.1111/crj.12568.

9. Orejas García C, Pascual Pascual T, Alzueta Alvarez A, et al. Cough variant asthma. Clinical and functional characteristics. Report of 63 cases. Arch Bronconeumol. 1998;34:232-6.

10. Global Strategy for Asthma Management and Prevention. http://ginas thma.org/2017-pocket-guide-for-asthma-management-andprevention/. Accessed 19 Jan 2017
11. Zhong N, Lai K, Chen R. The Chinese national guidelines of pulmonary function test. Chin J Tuberc Respir Dis. 2014;37:566-71.

12. Luo W, Chen $Q$, Chen R, et al. Reference value of induced sputum cell counts and its relationship with age in healthy adults in Guangzhou. Clin Respir J: South China; 2017.

13. De Diego A, Martínez E, Perpiñá M, et al. Airway inflammation and cough sensitivity in cough-variant asthma. Allergy. 2005;60:1407-11.

14. Dicpinigaitis PV. Chronic cough due to asthma: ACCP evidence-based clinical practice guidelines. Chest. 2006;129(1 Suppl):75S-9S.

15. Koh YY, Chae SA, Min KU. Cough variant asthma is associated with a higher wheezing threshold than classic asthma. Clin Exp Allergy. 1993;23:696-701.

16. Niimi A, Matsumoto $H$, Minakuchi $M$, et al. Airway remodelling in coughvariant asthma. Lancet. 2000:356:564-5.

17. Koh YY, Jeong JH, Park Y, et al. Development of wheezing in patients with cough variant asthma during an increase in airway responsiveness. Eur Respir J. 1999;14:302-8.

18. Lee SY, Kim MK, Shin C, et al. Substance P-immunoreactive nerves in endobronchial biopsies in cough-variant asthma and classic asthma. Respiration. 2003:70:49-53.

19. Takemura M, Niimi A, Matsumoto $H$, et al. Atopic features of cough variant asthma and classic asthma with wheezing. Clin Exp Allergy. 2007;37:1833-9.

20. Asthma Workgroup, Chinese Society of Respiratory Diseases (CSRD), Chinese Medical Association. The Chinese national guidelines on diagnosis and management of cough (December 2010). Chin Med J. 2011;124:3207-19.
Ready to submit your research? Choose BMC and benefit from:

- fast, convenient online submission

- thorough peer review by experienced researchers in your field

- rapid publication on acceptance

- support for research data, including large and complex data types

- gold Open Access which fosters wider collaboration and increased citations

- maximum visibility for your research: over 100M website views per year

At BMC, research is always in progress.

Learn more biomedcentral.com/submissions 